Article

\title{
Chitin Oligosaccharide Modulates Gut Microbiota and Attenuates High-Fat-Diet-Induced Metabolic Syndrome in Mice
}

\author{
Junping Zheng ${ }^{1,2,3}{ }^{\circledR}$, Gong Cheng ${ }^{3}$, Qiongyu $\mathrm{Li}^{3}$, Siming Jiao ${ }^{3}$, Cui Feng ${ }^{3}$, Xiaoming Zhao ${ }^{1}$, \\ Heng Yin ${ }^{1}$, Yuguang $\mathrm{Du}^{3, *}$ and Hongtao $\mathrm{Liu}^{3,4, *}$ \\ 1 Liaoning Provincial Key Laboratory of Carbohydrates, Dalian Institute of Chemical Physics, Chinese \\ Academy of Sciences, Dalian 116023, China; junpingzheng2013@163.com (J.Z.); zhaoxm@dicp.ac.cn (X.Z.); \\ yinheng@dicp.ac.cn (H.Y.) \\ 2 University of Chinese Academy of Sciences, Beijing 100049, China \\ 3 State Key Laboratory of Biochemical Engineering and Key Laboratory of Biopharmaceutical Production \& \\ Formulation Engineering, PLA, Institute of Process Engineering, Chinese Academy of Sciences, \\ Beijing 100190, China; gcheng@ipe.ac.cn (G.C.); qiongyulee@hotmail.com (Q.L.); smjiao@ipe.ac.cn (S.J.); \\ cfeng@ipe.ac.cn (C.F.) \\ 4 Zhengzhou Institute of Emerging Industrial Technology, Zhengzhou 450000, China \\ * Correspondence: ygdu@ipe.ac.cn (Y.D.); liuhongtao@ipe.ac.cn (H.L.); Tel.: +86-10-8254-5070 (Y.D. \& H.L.).
}

Received: 22 January 2018; Accepted: 17 February 2018; Published: 19 February 2018

\begin{abstract}
Gut microbiota has been proved to be an indispensable link between nutrient excess and metabolic syndrome, and chitin oligosaccharide (NACOS) has displayed therapeutic effects on multiple diseases such as cancer and gastritis. In this study, we aim to confirm whether NACOS can ameliorate high-fat diet (HFD)-induced metabolic syndrome by rebuilding the structure of the gut microbiota community. Male C57BL/6J mice fed with HFD were treated with NACOS $(1 \mathrm{mg} / \mathrm{mL})$ in drinking water for five months. The results indicate that NACOS improved glucose metabolic disorder in HFD-fed mice and suppressed mRNA expression of the protein regulators related to lipogenesis, gluconeogenesis, adipocyte differentiation, and inflammation in adipose tissues. Additionally, NACOS inhibited the destruction of the gut barrier in HFD-treated mice. Furthermore, $16 \mathrm{~S}$ ribosome RNA sequencing of fecal samples demonstrates that NACOS promoted the growth of beneficial intestinal bacteria remarkably and decreased the abundance of inflammogenic taxa. In summary, NACOS partly rebuilt the microbial community and improved the metabolic syndrome of HFD-fed mice. These data confirm the preventive effects of NACOS on nutrient excess-related metabolic diseases.
\end{abstract}

Keywords: chitin oligosaccharide; gut microbiota; high-fat diet; insulin resistance; metabolic syndrome

\section{Introduction}

Metabolic syndrome, characterized by at least three of five medical conditions (obesity, hypertension, hyperglycemia, insulin resistance, and dyslipidemia), quintuples the risk of type 2 diabetes mellitus [1]. Increasing data indicate that gut microbiota is necessary to maintain the metabolic homeostasis of a host [2]. For instance, germ-free mice are resistant to high-fat diet (HFD)-induced obesity [3], but are prone to gain weight after fecal transplantation from obese mice [4]. It was also reported that the population of pro-inflammatory bacteria was elevated, and the abundance of beneficial bacteria was decreased, in the gut of obese or diabetic mice [5-7]. Furthermore, it was proved that several beneficial bacteria, such as Bifidobacterium, Lactobacillus, and Akkermansia, independently ameliorated hyperglycemia, glucose intolerance, and insulin resistance in HFD-fed mice [8-11]. 
The gut barrier, which is mainly composed of mucus layers and tight junctions, is an indispensable structure that maintains the balance between hosts and their microbiome [12]. The mucus layer above epithelial cells is formed by glycosylated mucin [13]. During gut dysbiosis, the degradation of mucin is observed and is accompanied by a decreased abundance of Akkermansia muciniphila, which is an intestinal mucin-degrading bacterium and is involved in the maintenance of the mucus layer $[9,12]$. The tight junction is under the mucus layer and its integrity is mainly regulated by zonula occludens- 1 (ZO-1) and occludin. Evidence shows that the levels of ZO-1 and occludin in jejunum epithelia are reduced in ob/ob mice [14]. Noticeably, the corruption of each layer of the gut barrier can cause serious outcomes. Lipopolysaccharides (LPS), produced by intestinal bacteria, can easily penetrate into the circulatory system through a leaky barrier. The leaked LPS can trigger adipocyte inflammation and eventually lead to insulin resistance, or even diabetes [15]. Adipocyte inflammation is characterized by the transcriptional upregulation of pro-inflammatory cytokines, including COX-2, IL-6, MCP-1, and TNF- $\alpha[16]$.

One of the strategies for improving metabolic syndrome is to maintain the balance of the gut ecosystem [17]. To date, there have been a series of prebiotics developed to regulate the intestinal microbial community. Among them, galacto- and xylo-oligosaccharides have been found to boost the abundance of beneficial bacteria (Bifidobacterium, Lactobacillus, and Akkermansia) [18,19], and to improve the metabolic profile in HFD mice [20]. In comparison with expensive, first-line medicines for diabetic treatment, oligosaccharides are usually produced at a low cost and show non- or less toxicity in vivo. Thus, oligosaccharide prebiotics should play a critical role in preventing against metabolic diseases.

Chitin, a cellulose-like polysaccharide linked by $\beta$ 1-4 $\mathrm{N}$-acetylglucosamine, is present in the exoskeleton of crab and shrimp [21,22]. Via chitinase digestion, chitin oligosaccharide ( $N$-acetyl-chitooligosaccharide, NACOS) can be produced and further deacetylated into chitosan oligosaccharide (COS) [23]. COS with a low molecular weight $(<1000 \mathrm{Da})$ was reported to markedly inhibit glucose uptake by the intestine tract by suppressing the activities of pancreatic $\alpha$-amylase and small intestinal $\alpha$-glucosidase [24,25]. Additionally, COS increases insulin secretion by promoting the antioxidant capacity of the pancreas [26,27], and exerts anti-diabetic effects in $\mathrm{db} / \mathrm{db}$ mice and streptozotocin-injected rats [28]. Especially, COS displayed low subacute toxicity and no adverse effect in rats at large dosage [29]. As compared to the investigations on COS, less work has been done regarding NACOS. Thus far, limited studies suggest that NACOS can be developed as a potential functional food, or biological medicine, for the treatment of multiple diseases, such as cancer, gastritis, and Alzheimer's disease [30-32]. In addition, chitin-glucan fiber can ameliorate metabolic disorder in HFD-fed mice [33]. Furthermore, NACOS increased the ratio of Lactobacillus/Enterococcus in human fecal culture [34]. However, it remains to be seen whether NACOS can improve metabolic syndrome induced by nutritional excess.

Based on the above, we hypothesize that NACOS can alleviate metabolic disorder by modulating gut microbiota in HFD-fed mice. In this study, we assessed the suppressive effect of NACOS on HFD-induced disturbance in lipogenesis, gluconeogenesis, and inflammation in mice. Additionally, we explored the reshaping of the structure of unbalanced gut microbiota after NACOS treatment.

\section{Results}

\subsection{Effect of NACOS on Food Intake, Drinking Water, and Body Composition of HFD-Fed Mice}

To evaluate the effects of NACOS on metabolic syndrome, C57BL/6J mice were fed with HFD and were spontaneously treated with either a vehicle (sterile tap water) or NACOS. Referring to previous studies of NACOS and COS in mice [35,36], the concentration of $1 \mathrm{mg} / \mathrm{mL}$ NACOS (around $200 \mathrm{mg} / \mathrm{kg} /$ day, in drinking water) was used in this study. As compared with the CD group, the HFD group displayed an evidently higher body weight, which was prone to decrease after NACOS treatment (Figure 1A). During the treatment period, no significant differences in food intake and water drinking were observed among all groups (Figure 1B,C). On the other hand, NACOS feeding had no effect on 
the weight of liver or abdominal fat tissue in HFD-fed mice (Figure 1D,E). In addition, HFD feeding led to a dramatic decrease in pancreas mass ( $p<0.05$, vs. the CD group), which was greatly reversed using NACOS treatment ( $p<0.01$, vs. the HFD group) (Figure 1F).

A

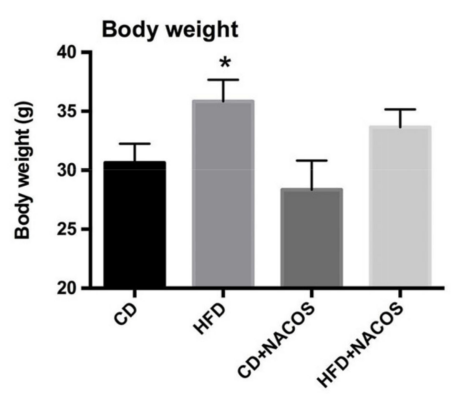

D

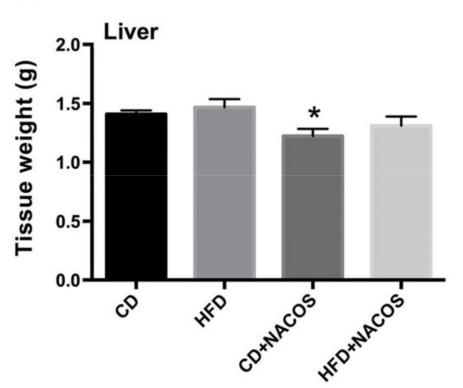

B

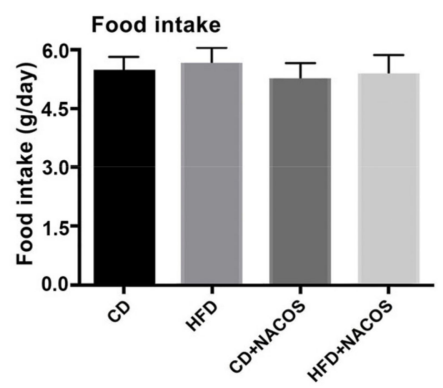

E

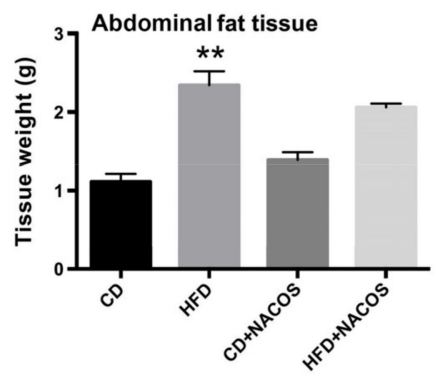

C

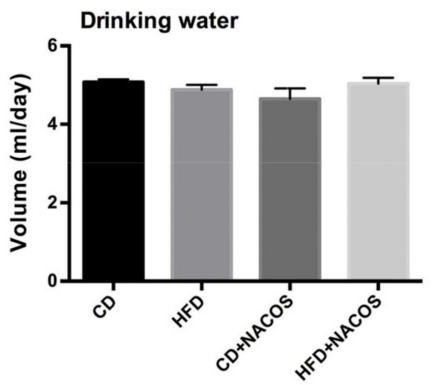

$\mathbf{F}$

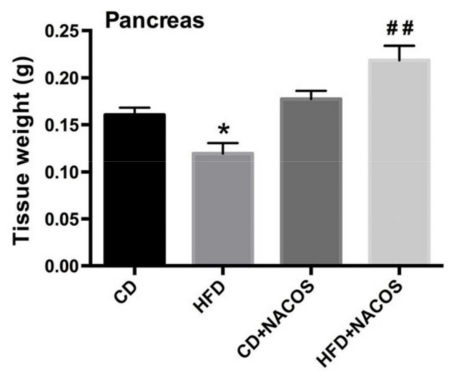

Figure 1. Effects of chitin oligosaccharide (NACOS) on body composition of high-fat diet (HFD)-fed mice. Mice were fed with normal chow diet (CD), HFD, CD + NACOS $(1 \mathrm{mg} / \mathrm{mL}$, in drinking water, about $200 \mathrm{mg} / \mathrm{kg} /$ day) or HFD + NACOS for five months. During the treatment period, body weight (A), diet consumption (B) and water drinking (C) were monitored for each group. After that, mice were euthanized for tissue collection, and the weights of liver (D), abdominal fat tissue (E), and pancreas (F) were detected. Data are represented as means $\pm \operatorname{SD}(n=5) .{ }^{*} p<0.05,{ }^{* *} p<0.01$ compared to the CD group; ${ }^{\# \#} p<0.01$ compared to the HFD group.

\subsection{NACOS Ameliorated Glucose Intolerance and Increased Insulin Secretion of HFD-Treated Mice}

During the treatment period, fasting glucose was monitored frequently until the hyperglycemic symptom was obvious in the HFD-fed group ( $p<0.05$, vs. the CD group) (Figure 2A). Compared with the HFD group, mice fed with HFD plus NACOS had a lower fasting glucose, which was nearly the equivalent of that in the CD group (Figure 2A). Further, a glucose tolerance test was carried out after fasting for $12 \mathrm{~h}$. Blood glucose was detected at indicated time points $(0 \mathrm{~min}, 15 \mathrm{~min}, 30 \mathrm{~min}$, $60 \mathrm{~min}$, and $120 \mathrm{~min}$ ) after intraperitoneal injection of glucose $(2 \mathrm{~g} / \mathrm{kg}$ body weight). As indicated in Figure 2B, the mice in the HFD group showed poorer behavior in terms of glucose tolerance at individual time points relative to that in the CD group, which was significantly improved by NACOS feeding. A similar result was found with respect to the area under the blood glucose response curve (Figure 2C). Next, the plasma insulin of each mouse was measured and it turned out that NACOS feeding strikingly promoted insulin secretion; notably higher than that of the HFD group $(p<0.01$, vs. the HFD group). 
A

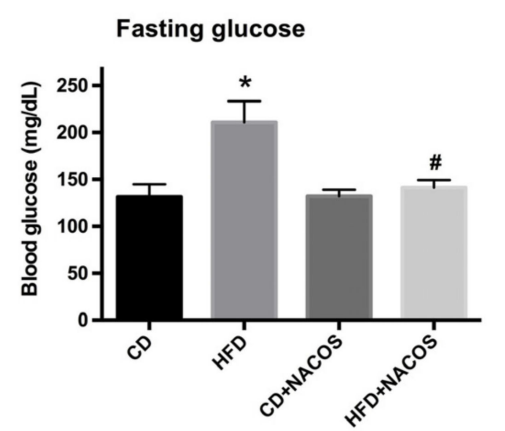

C

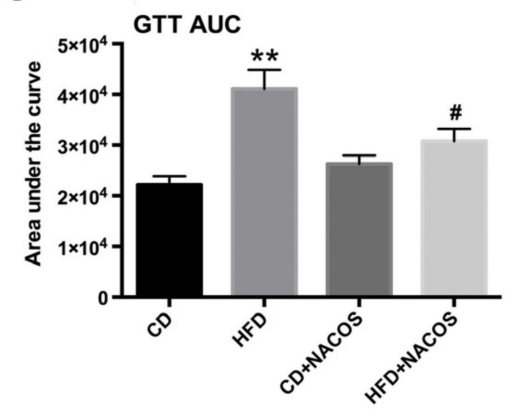

B

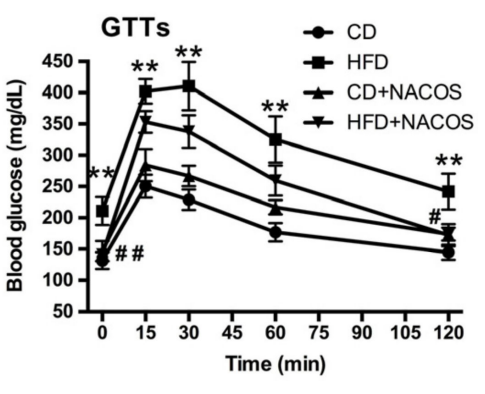

D

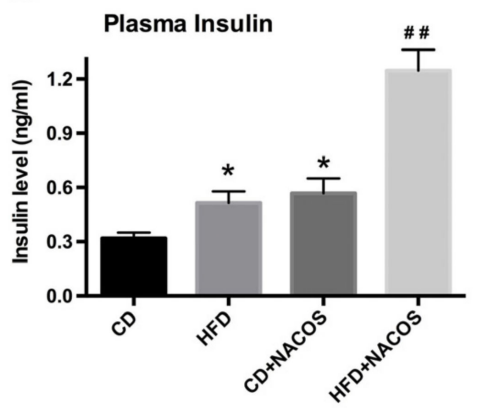

Figure 2. Effects of NACOS on glucose intolerance and insulin secretion of HFD-treated mice. Mice were fed with CD, HFD, CD + NACOS (1 mg/mL, in drinking water, about $200 \mathrm{mg} / \mathrm{kg} /$ day), or HFD + NACOS for five months. During the treatment period, fasting glucose (A) was measured. After that, a glucose tolerance test (B) was conducted and the areas under the glucose response curve $(\mathbf{C})$ were calculated at the indicated time points (0-120 $\mathrm{min})$ after intraperitoneal injection of glucose ( $2 \mathrm{~g} / \mathrm{kg}$. body weight). Finally, all mice were euthanized and plasma was collected for random insulin detection (D) using ELISA. Data are represented as means $\pm \operatorname{SD}(n=5) .{ }^{*} p<0.05,{ }^{* *} p<0.01$ compared to the CD group; ${ }^{\#} p<0.05,{ }^{\# \#} p<0.01$ compared to the HFD group.

\subsection{NACOS Alleviated Dyslipidemia in HFD-Fed Mice}

To determine how NACOS regulated the lipid or glucose metabolism of HFD-treated mice, the lipids in blood and liver tissues were determined (Figure S4). The results suggest that NACOS treatment significantly decreased HFD-induced hyper-triglyceride (Figure S4A,B) and reversed the decrease of high-density lipoprotein-cholesterol (HDL) in HFD-fed mice (Figure S4C). Further, abdominal fat tissues were collected for the analysis of lipogenesis protein regulators (Scd-1, stearoyl-CoA desaturase-1), adipocyte differentiation (C/EBP $\alpha, \mathrm{CCAAT} /$ enhancer-binding protein alpha; PPAR $\alpha$, peroxisome proliferator-activated receptor alpha; PPAR $\gamma$, peroxisome proliferator-activated receptor gamma), and gluconeogenesis (G6Pase, glucose-6-phosphatase; PEPCK, phosphoenolpyruvate carboxykinase). We found that NACOS treatment significantly inhibited up-regulation of the mentioned genes in HFD-treated mice at the mRNA level $(p<0.05$ or 0.01 , vs. the HFD group) (Figure 3A-F). Furthermore, NACOS suppressed HFD-induced over-expression of leptin mRNA in adipose tissue ( $p<0.05$, vs. the HFD group) (Figure 3G). Additionally, NACOS profoundly inhibited lipid accumulation in the liver (Figure S5) and reversed the hypertrophy of adipocytes in HFD-fed mice (Figure S6). 
A

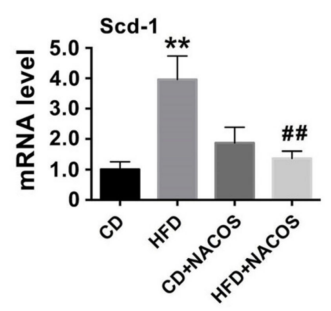

E

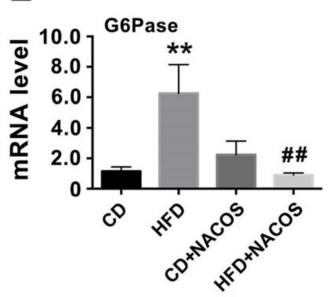

B

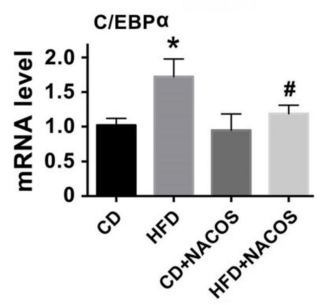

$\mathbf{F}$

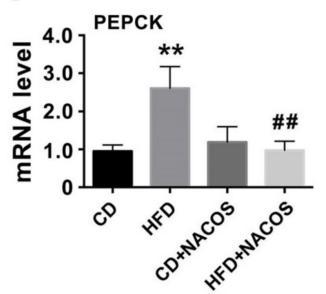

C

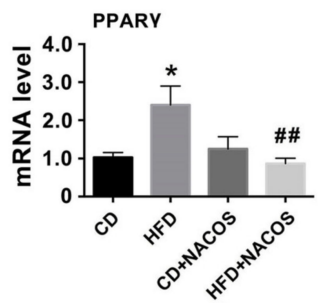

G

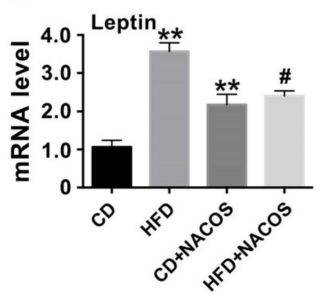

D

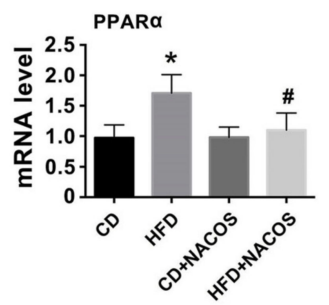

Figure 3. Effects of NACOS on lipid/glucose metabolism-related markers at the transcription level in the abdominal adipose tissues of HFD-treated mice. Mice were fed with CD, HFD, CD + NACOS $(1 \mathrm{mg} / \mathrm{mL}$, in drinking water, about $200 \mathrm{mg} / \mathrm{kg} /$ day), or HFD + NACOS for five months. After treatment, mice were euthanized and the abdominal adipose tissues were collected for mRNA detection of lipid/glucose metabolism-related markers by RT-PCR analysis, including Scd-1 (A), C/EBP $\alpha$ (B), $\operatorname{PPAR} \gamma(\mathbf{C}), \operatorname{PPAR} \alpha(\mathbf{D})$, G6Pase (E), PEPCK $(\mathbf{F})$, and leptin (G). Data are represented as means $\pm \mathrm{SD}$ $(n=5) .{ }^{*} p<0.05,{ }^{* *} p<0.01$ compared to the CD group; ${ }^{*} p<0.05,{ }^{\# \#} p<0.01$ compared to the HFD group.
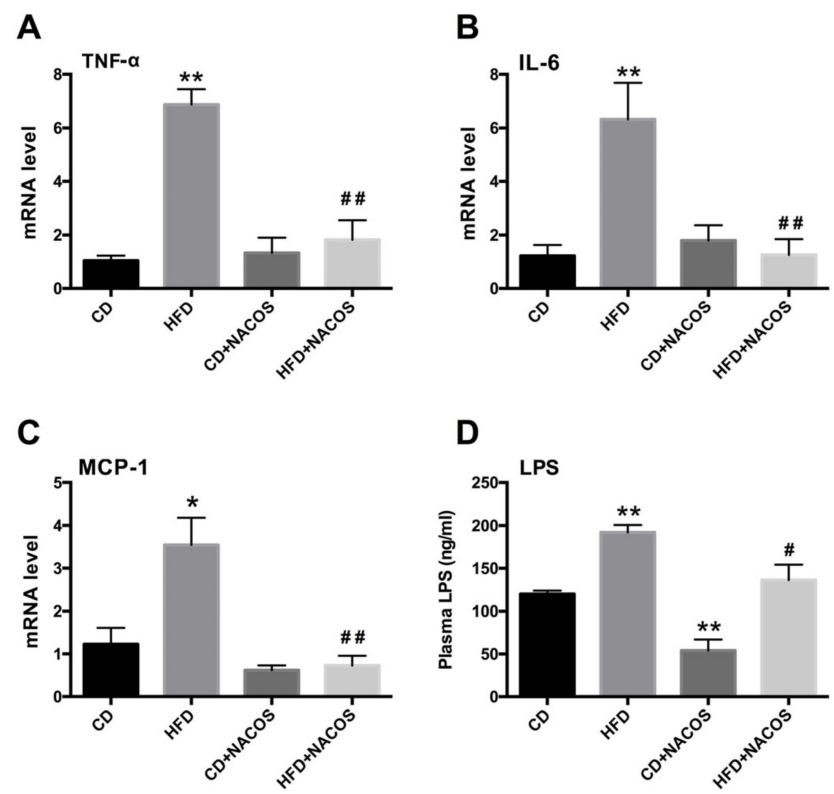

Figure 4. Inhibition of inflammatory responses in abdominal adipose tissue and decrease of plasma LPS in HFD-fed mice by NACOS treatment. Mice were fed with CD, HFD, CD + NACOS (1 mg/mL, in drinking water, about $200 \mathrm{mg} / \mathrm{kg} /$ day), or HFD + NACOS for five months. After the treatment, mice were euthanized. The abdominal adipose tissues were collected for mRNA detection of pro-inflammatory cytokines by RT-PCR analysis, including TNF- $\alpha$ (A), IL-6 (B), and MCP-1 (C). The blood was collected for LPS detection (D) by ELISA. Data are represented as means $\pm \operatorname{SD}(n=5)$. ${ }^{*} p<0.05,{ }^{* *} p<0.01$ compared to the CD group; ${ }^{\#} p<0.05,{ }^{\# \#} p<0.01$ compared to the HFD group. 


\subsection{NACOS Attenuated Inflammation in HFD-Fed Mice}

Inflammation usually leads to dyslipidemia of adipocyte tissue [37]. In the present study, the mRNA expression of pro-inflammatory cytokines in adipose tissues was analyzed. As shown in Figure 4, significantly increased levels of tumor necrosis factor alpha (TNF- $\alpha$ ), interleukin 6 (IL-6), and monocyte chemoattractant protein 1 (MCP-1) were observed in the HFD group, which were strongly reduced by NACOS treatment ( $p<0.05$ or 0.01 , vs. the HFD group) (Figure $4 A-C$ ). We also monitored LPS levels in the circulatory system, and the result suggests that NACOS significantly decreased the blood concentration of LPS in HFD-fed mice (Figure 4D).

B
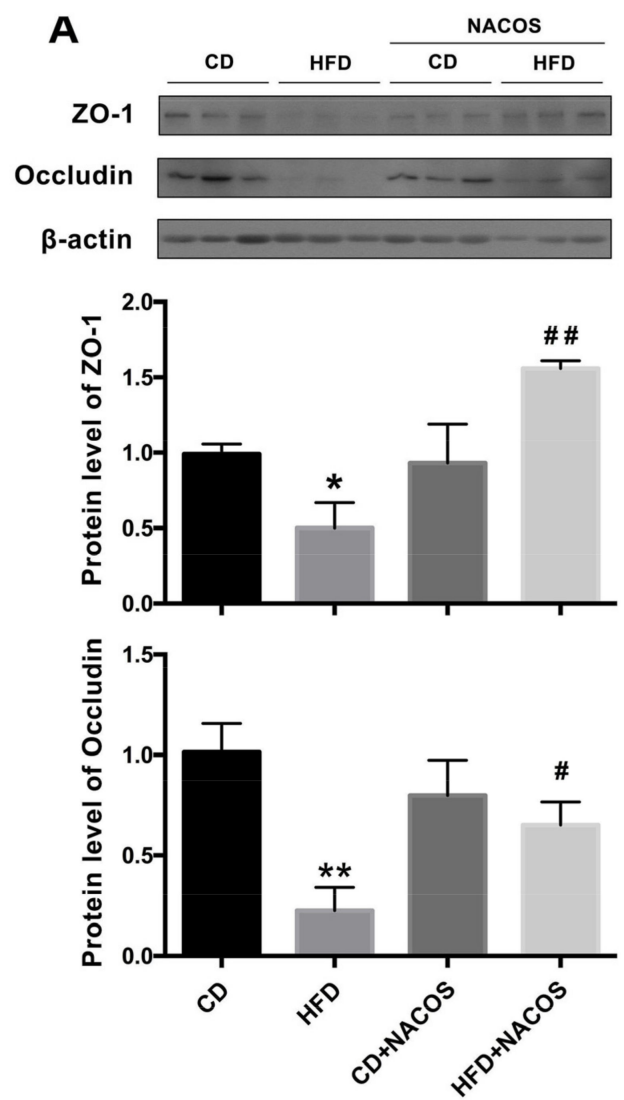

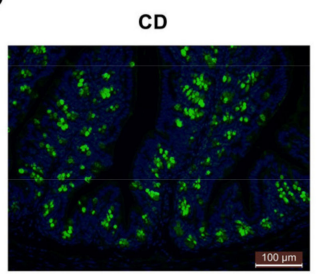

CD+NACOS

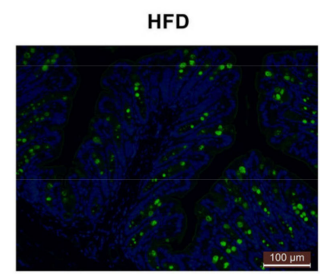

HFD+NACOS
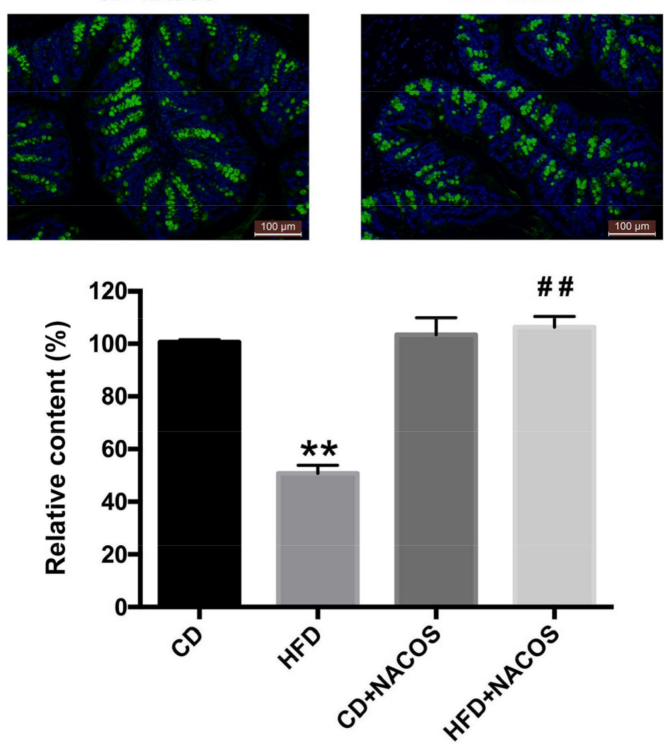

Figure 5. Improvement of gut barrier damage of HFD-fed mice by NACOS administration. Mice were fed with CD, HFD, CD + NACOS ( $1 \mathrm{mg} / \mathrm{mL}$, in drinking water, about $200 \mathrm{mg} / \mathrm{kg} /$ day), or HFD + NACOS for five months. After treatment, mice were euthanized and the intestinal segments (jejunum and colon) were collected for further analysis. (A) Effects of NACOS on the protein expression of ZO-1 and occludin in intestinal tissues of HFD-fed mice by Western blot analysis. (B) Effect of NACOS on the damage to intestinal mucus layer in HFD-fed mice by WGA-FITC staining. The contents of mucin glycoproteins were reflected by the fluorescence intensity of each slide. Green fluorescence, mucin glycoprotein staining; blue fluorescence, nucleus staining. Data are represented as means $\pm \mathrm{SD}(n=5)$. ${ }^{*} p<0.05,{ }^{* *} p<0.01$ compared to the CD group; ${ }^{\#} p<0.05,{ }^{\# \#} p<0.01$ compared to the HFD group.

\subsection{NACOS Protected Intestinal Integrity in HFD-Fed Mice}

Evidence shows that low-grade inflammation may be attributed to the impairment of gut integrity [38]. To study the role of NACOS in modulating the intestinal tight junction of HFD-fed mice, the proximal colon was collected for the detection of major tight junction proteins, including ZO-1 and occludin, via Western blot analysis. Results show that the protein levels of both ZO-1 and occludin were considerably decreased in the HFD group, and were partly normalized by NACOS feeding ( $p<0.05$, vs. the HFD group) (Figure 5A). Furthermore, the mucus layer was stained with 
wheat germ agglutinin labeled with FITC (WGA-FITC) to visualize the impairment of the intestinal barrier. Green signals represented mucin glycoproteins and blue signals showed nucleus location using DAPI staining. Results indicated that NACOS significantly inhibited the decrease in green fluorescence intensity of HFD-fed mice, suggesting that NACOS treatment prevented damage to the intestinal mucus layer (Figure 5B).

\subsection{NACOS Protected Gut Microbiota from Destruction in HFD-Fed Mice}

Increased intestinal permeability is generally caused by gut dysbiosis. To unveil the protective effect of NACOS on maintenance of gut microbiota composition in HFD-fed mice, 16S rRNA gene sequencing of fecal samples was carried out. Remarkably, principal component analysis based on operational taxonomic unit (OTU) abundance indicated that the microbial composition was distinctly separated among all experimental groups. Further, the relative abundance of bacteria at the phylum level was obviously different (Figure 6B). The ratio of Fimicutes/Bacteroidetes was statistically decreased in the HFD group, which was almost completely restored in the HFD+NACOS group (Figure 6B). On the other hand, NACOS feeding profoundly suppressed the growth of Proteobacteria induced by HFD (Figure 6B). In addition, NACOS feeding slightly increased the abundance of Verrucomicrobia in comparison with the HFD group (Figure 6B).

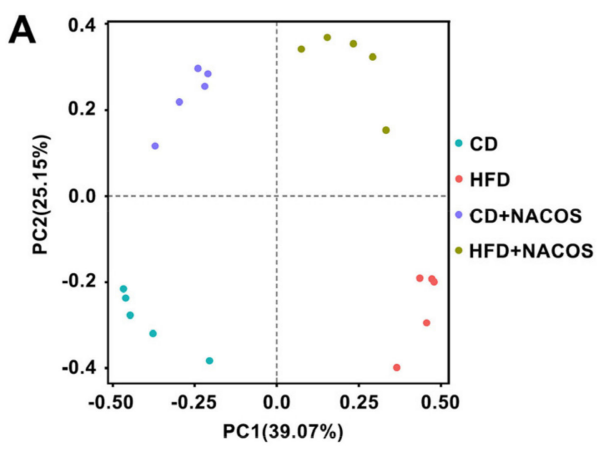

B

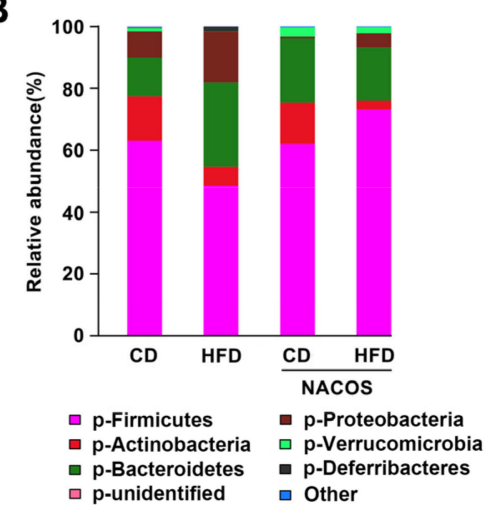

C

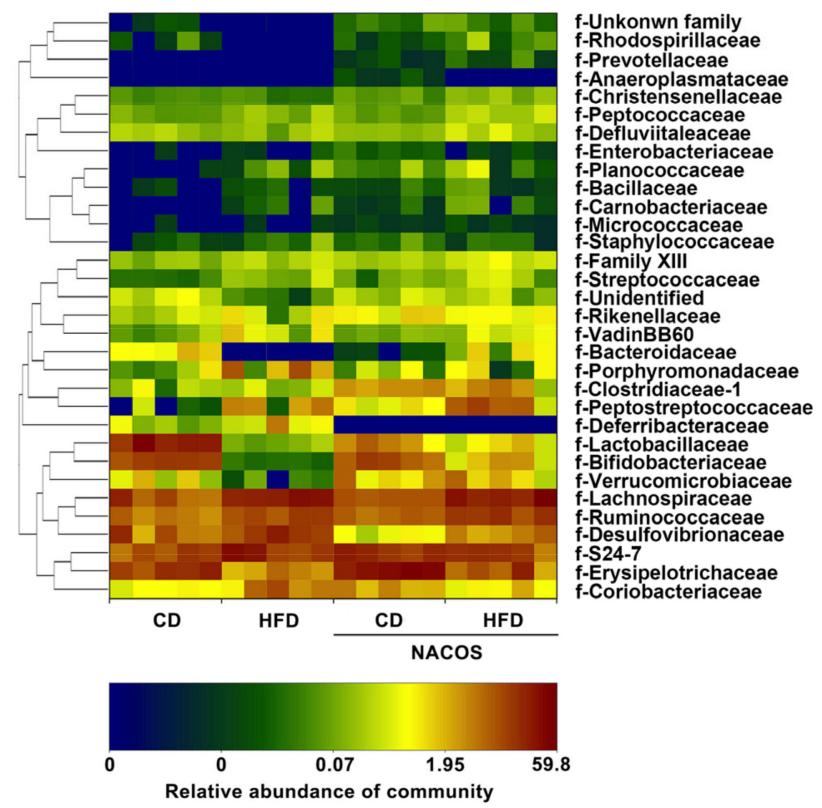

Figure 6. Inhibitory effects of NACOS on the imbalance of gut microbiota of HFD-fed mice. Mice were fed with CD, HFD, CD + NACOS $(1 \mathrm{mg} / \mathrm{mL}$, in drinking water, about $200 \mathrm{mg} / \mathrm{kg} /$ day), or HFD + NACOS for five months. After the treatment, mice were euthanized and the fecal contents were collected for $16 \mathrm{~S}$ rRNA sequence analysis. (A) Bacterial community assay using the principal component analysis; (B) bar plot of microbial community at phylum level; (C) relative abundance of each classified family using heat map analysis.

Next, to determine which bacterial families shaped the distinct microbiota structures between four groups, the relative abundances of bacteria families were tabulated on a heat map (Figure 6C). It was found that 11 families displayed significantly different abundances between the HFD group and the HFD + NACOS group, indicating that the protective effect of NACOS on mouse 
metabolic syndrome may be mediated by a subset of bacterial taxa. The relative abundances of Rhodospirillaceae, Christensenellaceae, Bacteroidaceae, Lactobacillaceae, Bifidobacteriaceae, Verrucomicrobiaceae, and Erysipelotrichaceae were decreased by HFD treatment, while NACOS rescued these HFD-induced changes to a large extent. Contrary to this, HFD treatment increased the abundances of Porphyromonadaceae, Deferribacteraceae, Desulfovibrionaceae, and Coriobacteriaceae, all of which were restored to normal levels by NACOS.

Furthermore, several bacteria including Bifidobacterium, Lactobacillus, Akkermansia, Bacteroides, Desulfovibrio, and Allobaculum at the genus level were selected for further analysis. It was suggested that the abundances of four beneficial bacteria, Bifidobacterium (Figure 7A), Lactobacillus (Figure 7B), Akkermansia (Figure 7C), and Bacteroides (Figure 7D), were reduced in the HFD group $(p<0.05$, vs. the CD group), which was significantly promoted after NACOS treatment (Figure 7A-D). NACOS also distinctly reduced the abundance of Desulfovibrio in HFD-fed mice (Figure 7E), but had no effect on Allobaculum (Figure 7F). Moreover, NACOS displayed similar restoring effects on the changes of other low-abundant genera in the HFD group (Figure S7).

A

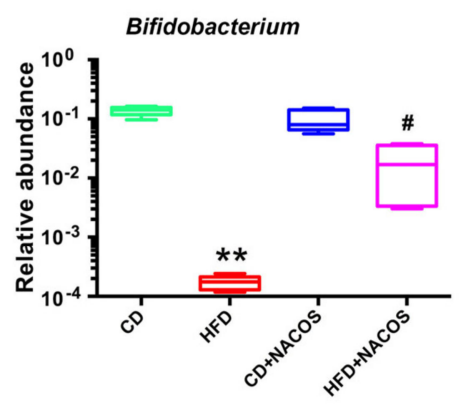

D

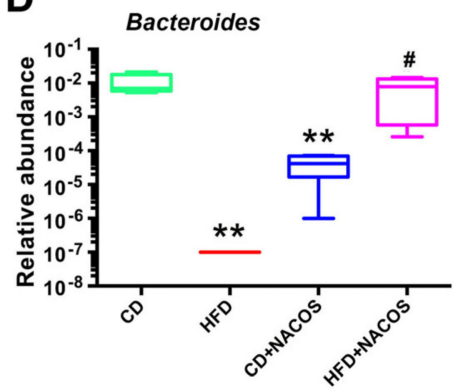

B

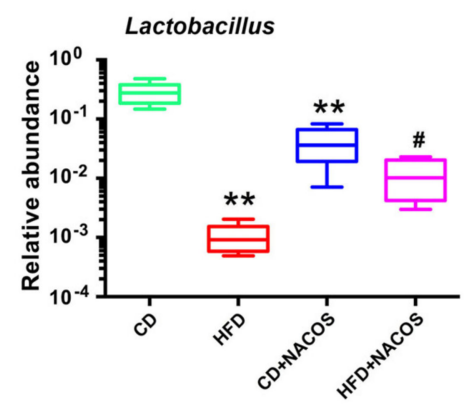

E

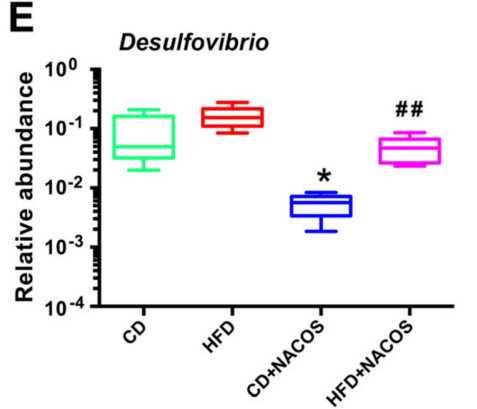

C

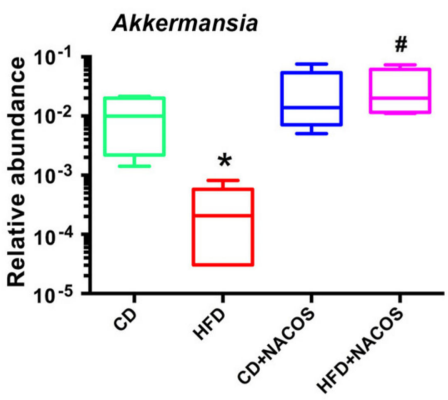

F

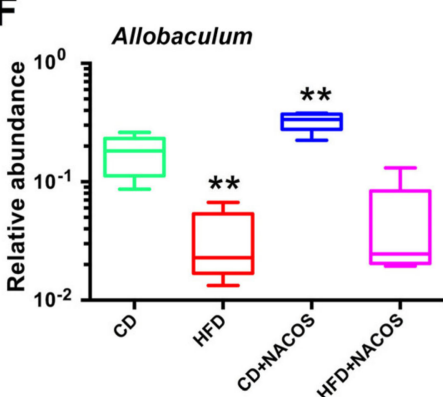

Figure 7. Effects of NACOS on the relative abundance of gut microbial community at genus level in HFD-fed mice, including Bifidobacterium (A), Lactobacillus (B), Akkermansia (C), Bacteroides (D), Desulfovibrio (E), and Allobaculum (F). Mice were fed with CD, HFD, CD + NACOS (1 mg/mL, in drinking water, about $200 \mathrm{mg} / \mathrm{kg} /$ day) or HFD + NACOS for five months. After the treatment, mice were euthanized and the fecal contents were collected for $16 \mathrm{~S}$ rRNA sequencing. ${ }^{*} p<0.05,{ }^{* *} p<0.01$ compared to the CD group; ${ }^{\#} p<0.05,{ }^{\# \#} p<0.01$ compared to the HFD group.

\subsection{Correlation between Gut Microbiota and Metabolic Parameters}

To further explore the correlation between specific bacterial taxa and metabolic parameters, we tabulated the Spearman correlation heat map and selected several tropical markers related to the tight junction (ZO-1 and occludin), inflammation (LPS), and glucose metabolism (Figure 8). There were three distinct clusters based on the strong correlation between genera and metabolic parameters. Cluster 1, including Bosea, Blautia, Odoribacter, Desulfovibrio, Gordonibacter, and Jeotgalicoccus, showed a positive relationship with LPS, glucose levels, and body weight, and negative a relationship with occludin, ZO-1, and pancreas weight. Cluster 2, including Alistipes, Bacteroides, Lactobacillus, Parvibacter, Bifidobacterium, and Allcobaculum, indicated the opposite effect as that of Cluster 1. Cluster 3, containing 
Christensenella, Anaerovorax, Prevotella, mouse gut metagenome, Thalassospira, Candidatus Saccharimonas, and Akkermansia, suggested a positive correlation with insulin levels and pancreas weight.
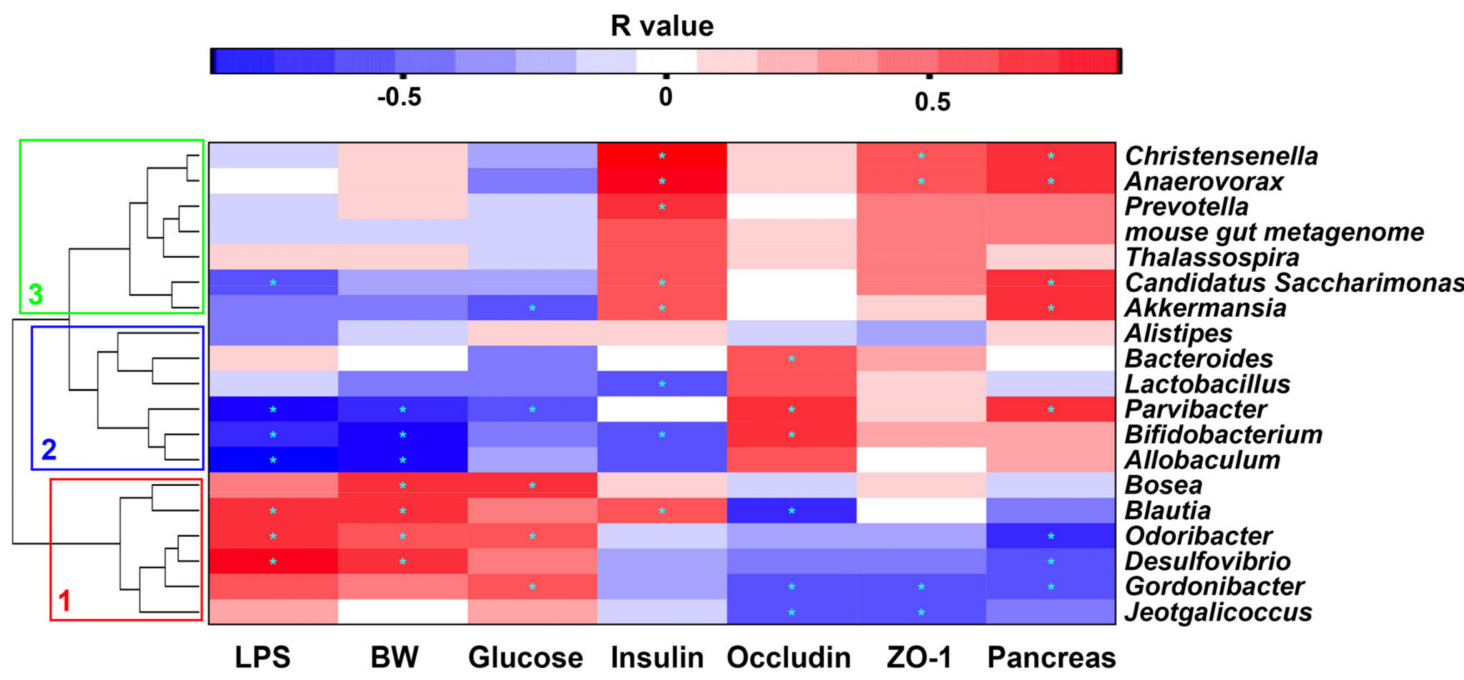

Figure 8. Correlation between metabolic biomarkers and relative abundance of intestinal bacteria at the genus level. The genera were distinctly divided into three clusters (cluster 1: red frame, cluster 2: blue frame, cluster 3: green frame). BW: body weight; LPS: lipopolysaccharide. The color of cells represents correlation $R$ values from (-1)-0-1 (blue-white-red). Cells marked with an asterisk show significance following Spearman correlation for multiple comparisons, $p<0.05$.

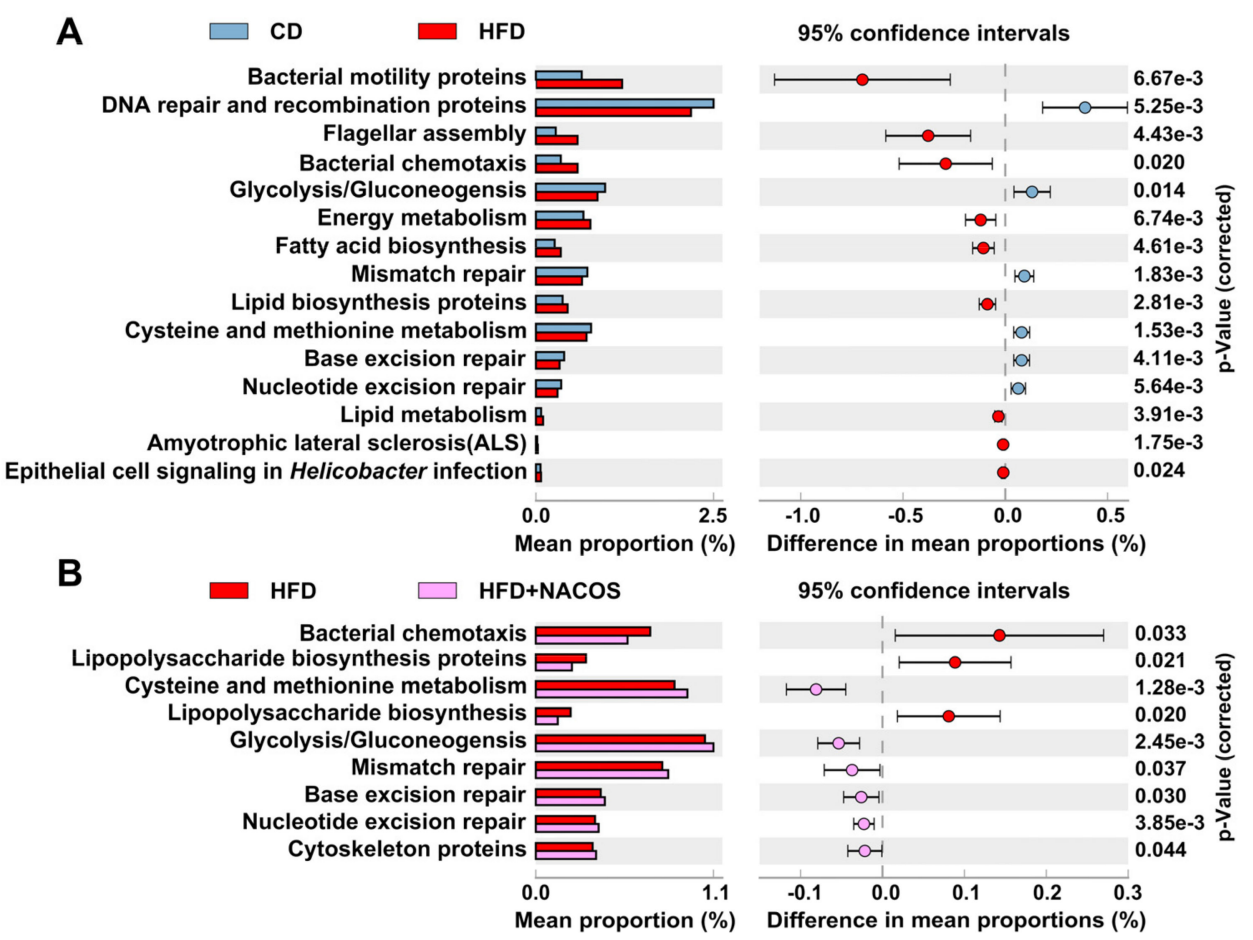

Figure 9. Prediction of changed KEGG pathways using PICRUSt analysis. (A) A total of 15 KEGG pathways were significantly changed in the HFD group compared with the CD group; (B) a total of nine KEGG pathways were significantly recovered in the HFD+NACOS group (bar plots on the left side displayed the mean proportion of each KEGG pathway. Dot plots on the right show the differences in mean proportions between the two indicated groups using $p$-values). 
In order to gain a more fundamental understanding of the altered gut microbiota, we predicted their functional profiles using PICRUSt (Phylogenetic Investigation of Communities by Reconstruction of Unobserved States) analysis. As shown in Figure 9A, based on the composition of gut microbiota, 15 Kyoto Encyclopedia of Genes and Genomes (KEGG) pathways of gut microbiota were estimated to be affected in the HFD group. These pathways included bacterial motility (bacterial motility proteins, flagellar assembly, and bacterial chemotaxis), oxidative stress (DNA repair, mismatch repair) and energy metabolism (glycolysis/gluconeogensis, lipid metabolism, and fatty acid biosynthesis) (Figure 9A). Interestingly, it seems that NACOS treatment significantly influenced bacterial motility (bacterial chemotaxis), oxidative stress (nucleotide excision repair), energy metabolism (glycolysis/gluconeogensis), and inflammation process (lipopolysaccharide biosynthesis) (Figure 9B).

\section{Discussion}

Thus far, NACOS has displayed a series of pharmacological effects, such as antimicrobial activity and protection against pathogen-induced infection [39]. As one of the major chitinous products, most recent studies focused on the biological activities of NACOS for its wide applications in various fields [40]. In this study, we, for the first time, demonstrated that NACOS attenuated HFD-induced metabolic syndrome, which may be related to the modulation of gut microbiota community.

Here, we proved that NACOS treatment, not only suppressed glucose intolerance, but directly lowered fasting blood glucose in HFD-fed mice (Figure 2A-C), indicating the improvement of glucose homeostasis in vivo. On the other hand, NACOS promoted the production of random plasma insulin in mice fed with a control diet or HFD. Though up-regulated insulin levels usually reflect impairment of insulin sensitivity, we speculate that the increase in insulin secretion should help to reduce the blood glucose of mice, instead of impairing insulin sensitivity, which can be indirectly proven by the inhibition of hyperglycemia and the improvement of glucose intolerance in HFD-fed mice after NACOS treatment. It was reported that COS stimulated glucose-inducible insulin expression of beta-cells in diabetic rats with streptozotocin injection [41]. Considering the promoting effect of COS on insulin production, it is possible that the anti-diabetic effects of NACOS may also be associated with increased insulin secretion and elevated proliferation of islets beta-cells in diabetic mice. This can be partly reflected by the increase of pancreatic mass in HFD-fed mice after NACOS treatment (Figure 1F), and this should be confirmed in future work.

In general, long-term intake of high-energy foods will increase the risk of metabolic syndrome, characterized by symptoms, such as hyperglycemia, dyslipidemia, obesity, and glucose intolerance. Since HFD feeding can simulate the energy-dense food of human beings (e.g., a Western diet and fast food) to a large extent, we fed mice with HFD for five months to induce metabolic disorders. We found that NACOS alleviated the dyslipidemia of HFD-fed mice by reducing triglyceride levels in blood and liver tissues (Figure S4) and blocking the transcription of several genes related to lipogenesis, adipocyte differentiation, and gluconeogenesis (Figure 3). In combination with reducing weight, NACOS displayed the potential to be a functional food or biological medicine to prevent the occurrence of metabolic diseases. Since inflammatory response has been demonstrated to be a key contributor to metabolic syndrome, we further examined the effects of NACOS on the expression of pro-inflammatory cytokines in adipose tissues. The results showed that NACOS dramatically reduced the mRNA levels of cytokines, including TNF- $\alpha$, IL-6, and MCP-1, and also significantly decreased plasma concentrations of LPS in HFD-fed mice (Figure 4). The LPS in circulatory system originally came from Gram-negative bacteria via pathogenic invasion of the leaky gut barrier [42]. Indeed, in this study, we observed the reduction of major tight junction proteins (ZO-1 and occludin) and damage to the mucus layer of the proximal colon in HFD-fed mice, which were significantly suppressed by NACOS treatment (Figure 5). It was indicated that the strengthening of the intestinal barrier may be the reason for reduced LPS concentrations in blood and in the attenuated inflammation of adipose tissues of HFD-fed mice. 
Normally, the lifespan of mouse is two to three years, which means that mice aged six months can be still regarded as "young adults". It was recently reported that the fecal microbial composition varied little in the first year of healthy rats (with 2.5-3 years of the lifespan) [43]. Therefore, in this study, the metabolic data of gut microbiota in mice were determined after five months of treatment (six months old).

Gut microbial composition can be changed by altered phyla ratios, which further enhances the pro-inflammatory potential of harmful intestinal bacteria [44]. There are contradictory conclusions regarding the change of Firmicutes/Bacteroidetes (F/B) ratios when the adiposity occurred. For example, Koropatkin et al. [45] reported that an increased ratio of F/B promoted the development of obesity in mice. In other studies, a low F/B ratio was identified in obese mice or people $[46,47]$. In our research, HFD feeding decreased the ratio of $F / B$, which was restored by NACOS treatment (Figure 6B). Further, at the family level, the reduced abundances of Porphyromonadaceae, Deferribacteraceae, Coriobacteriaceae, and the increased abundances of Rhodospirillaceae, Christensenellaceae, Bacteroidaceae, Lactobacillaceae, Bifidobacteriaceae, Verrucomicrobiaceae, and Erysipelotrichaceae, seen in HFD-fed mice, were also reversed by NACOS treatment (Figure 6C). The above results indicate that the direct modulating effects of NACOS on gut microbiota may play a critical role in the prevention of metabolic syndrome.

Evidence suggests that the increased abundances of Bifidobacterium, Lactobacillus, Akkermansia muciniphila, and Bacteroides were positively related to intestinal integrity, glucose tolerance, or attenuated obesity $[2,9,14,48-52]$. It is generally accepted that prebiotics usually promote the growth of beneficial intestinal bacteria, such as Lactobacillus and Bacteroides [53]. In this study, NACOS dramatically increased the abundances of Bifidobacterium, Lactobacillus Akkermansia, and Bacteroides in HFD-fed mice (Figure 7). In addition, the Gram-negative Desulfovibrio genus is commonly increased following a fat-enriched diet [54], and is responsible for inflammation due to its lipid A structures of LPS [55]. In accordance with these reports, our study showed that NACOS significantly reduced the abundance of the Desulfovibrio genus in both the CD group and the HFD group (Figure 7E). Noticeably, NACOS evidently reduced the abundance of Bacteroides and increased that of Allobaculum belonging to Firmicutes phylum in the CD group (Figure 7D,F). Similar results were also observed in studies on ginseng polysaccharides and inulin-type fructans [56,57], which are widely used prebiotics. This further demonstrated the complexity of gut microbiota in modulating the health of a host.

The correlation heat map between intestinal taxa and metabolic parameters indicated the different effects of bacteria. Our results suggested that Desulfovibrio had a close relationship with LPS biosynthesis pathway (Figure 8), so the reduced abundance of Desulfovibrio by NACOS treatment may contribute to reduction of LPS biosynthesis (Figure 9B).

The prediction of functional profiles, based on gut microbiota composition, was consistent with our experimental result that less LPS was detected in the plasma of HFD-fed mice with NACOS treatment. The PICRUSt analysis predicted that altered gut microbiota by NACOS showed less bacterial motility, LPS production, and oxidative stress. Our experimental results indicate that the ultimate outcome of NACOS treatment was the improvement of metabolic syndrome in HFD-fed mice (Figure 9).

In some of the studied parameters, NACOS had a slight opposite effect between CD + NACOS group and HFD + NACOS such as abdominal fat tissue (Figure 1E), GTT AUC (Figure 2C) and plasma insulin (Figure 2D). Usually, some polysaccharides or oligosaccharides displayed two-way regulatory effects on the host, for example, the inflammation-stimulating effects under physiological conditions and the anti-inflammatory effects under pathological conditions. This may partly explain why NACOS displayed a different effect on ND-fed mice as compared to that on HFD-fed mice. In addition, the Spearman correlation analysis in Figure 8 suggested that the parameters including LPS, BW, glucose and insulin were strongly correlated with the intestinal microbiota. And the levels of the above parameters were in accordance with the changes of Lactobacillus (Figure 7B), Bacteroides (Figure 7D), Desulfovibrio (Figure 7E), and Allobaculum (Figure 7F) between four experimental groups. 


\section{Materials and Methods}

\subsection{Reagents}

Chitin oligosaccharide with the polymerization degree 2-6 was prepared in our laboratory (Figure S3). Antibodies against ZO-1, occludin, and $\beta$ actin were purchased from Santa Cruz Biotechnology (Santa Cruz, CA, USA). Other antibodies, including horseradish peroxidase (HRP)-conjugated goat anti-rabbit IgG and HRP-conjugated goat anti-mouse IgG, were purchased from Cell Signaling Technology (Beverly, MA, USA). All other regular chemicals used in this study were of the highest chemical grade.

\subsection{Mouse Treatment}

Male C57BL /6J (20 \pm 2 g, six weeks old) mice were purchased from Model Animal Research Center of Nanjing University (Nanjing, China). Mice were given water and food ad libitum throughout the experiment. After acclimation for one week at $22 \pm 1{ }^{\circ} \mathrm{C}$ with a 12:12-h dark-light cycle, 20 mice were randomly divided into four groups $(n=5)$ : normal chow diet (CD) group, high-fat diet (HFD) group, CD + NACOS (1 mg/mL in drinking water, about $200 \mathrm{mg} / \mathrm{kg} / \mathrm{d})$ group and HFD + NACOS group. The standard CD contained $20 \%$ protein, $70 \%$ carbohydrate, and $10 \%$ fat, whereas the HFD contains $20 \%$ protein, $35 \%$ carbohydrate, and $45 \%$ fat. Both diets used in the experiment were purchased from Aoke Xieli Co., Ltd. (Beijing, China). Detailed ingredients of the diets can be found in Table S1. During the treatment period, body weight, and fasting glucose were measured frequently. Drinking water and diet consumption were recorded every other week. After treatment for five months, all mice were euthanized. Mouse sera were isolated and major tissues were collected, including liver, abdominal adipose tissues, pancreas, intestinal tract, and fecal samples. All samples were stored at $-80^{\circ} \mathrm{C}$ for further experiments.

The procedure for animal experiments was approved by the Animal Ethical Experimentation Committee of Institute of Process Engineering, Chinese Academy of Sciences (permission number: SYXK2015-0002) and in accordance with the National Act on Use of Experimental Animals (China).

\subsection{Glucose Tolerance Test and ELISA Assay}

A glucose tolerance test (GTT) was carried out at the end of the experiment. Briefly, after the mice fasted overnight, blood glucose was measured at $0 \mathrm{~min}, 15 \mathrm{~min}, 30 \mathrm{~min}, 60 \mathrm{~min}$, and $120 \mathrm{~min}$ after intraperitoneal injection of glucose $(2 \mathrm{~g} / \mathrm{kg}$ body weight). Blood was collected from the tail vein, and the glucose concentration of each sample was determined using a blood glucometer (Roche Diagnostics, Basel, Switzerland).

Plasma insulin levels were detected using a mouse ultrasensitive insulin ELISA kit (ALPCO, USA), and the plasma endotoxin concentration was measured using a mouse LPS ELISA kit (BlueGene Biotech, China) following the manufacturer's protocol. The concentrations of triglyceride and high-density lipoprotein cholesterol in the serum and liver tissues were determined using a Cobas 8000 modular series analyzer (Roche Diagnostics, USA).

\subsection{RNA Extraction and Quantitative Real-Time PCR (qRT-PCR)}

Total RNA was extracted from abdominal adipose tissue using TRIzon Reagent (CWBio, Beijing, China), and $5 \mu \mathrm{g}$ of RNA was transcribed to cDNA following the protocol of the HiFiScript cDNA synthesis kit (CWBio, Beijing, China). Polymerase reaction was performed using a SYBR Select Master Mix (Applied Biosystems,Foster City, CA, USA) with the following thermal cycle conditions: $95^{\circ} \mathrm{C}$ for 5 min; 40 cycles of amplification $\left(95^{\circ} \mathrm{C}\right.$ for $15 \mathrm{~s}, 60^{\circ} \mathrm{C}$ for $\left.60 \mathrm{~s}\right)$. The fluorescence intensity was captured and analyzed using a 7500 Fast Real-Time PCR system (Applied Biosystems, Foster City, CA, USA). The mRNA expression levels of stearoyl-CoA desaturase-1 (Scd-1), CCAAT/enhancer-binding protein alpha $(\mathrm{C} / \mathrm{EBP} \alpha)$, peroxisome proliferator-activated receptor gamma (PPAR $\gamma$ ), peroxisome proliferator-activated receptor alpha $(\operatorname{PPAR} \alpha)$, glucose-6-phosphatase (G6Pase), phosphoenolpyruvate 
carboxykinase (PEPCK), leptin, tumor necrosis factor alpha (TNF- $\alpha$ ), interleukin 6 (IL-6), and monocyte chemoattractant protein 1 (MCP-1) were normalized using $\beta$-actin as an internal control, and the primer sequences are given in Table S2. The relative fold difference of mRNA was calculated using the comparative $\mathrm{Ct}$ method and is expressed as $2^{-\Delta \Delta \mathrm{Ct}}$.

\subsection{Western Blotting}

One hundred micrograms of intestinal tissue were homogenized with RIPA buffer (Cell Signaling, MA, USA). About $40 \mu \mathrm{g}$ of protein lysates was fractionated on $8 \%$ sodium dodecyl sulfate-polyacrylamide gel (SDS-PAGE) and transferred to polyvinylidene fluoride membrane (Millipore, Bedford, MA, USA) for Western blot analysis. Membranes were probed with primary antibodies against ZO-1, occludin and $\beta$-actin overnight at $4{ }^{\circ} \mathrm{C}$, followed by incubation with horseradish peroxidase-conjugated secondary antibody. Protein bands were captured using enhanced chemiluminescence (ECL) (Cell Signaling Technology, Danvers, MA, USA) and densitometry analysis was conducted using Image J2x software (National Institute of Health, Bethesda, MD, USA).

\subsection{Immunofluorescent Staining}

For immunofluorescent staining, the proximal colon segments, fixed in $4 \%$ paraformaldehyde, were sliced and trimmed into serial sections. After being deparaffinized in xylene and rehydrated through ascending ethanol series, the slides were permeabilized with $0.1 \%$ Triton-X 100 for 5 min, blocked with 10\% goat serum in PBST (PBS with $0.05 \%$ Tween 20) for $1 \mathrm{~h}$, and incubated with WGA-FITC (1:1000) at $4{ }^{\circ} \mathrm{C}$ overnight, which can specifically identify the glycans of mucin. Washed with PBST, the coverslips were mounted with anti-fade reagent with $4^{\prime}$, $6^{\prime}$-diamidino-2-phenylindole (DAPI) (Life Technologies, Waltham, MA, USA). Images were acquired using a Leica DFC310 FX digital camera connected to a Leica DMI4000 B light microscope (Wetzlar, Germany). The contents of mucin glycoproteins were reflected by the fluorescence intensity of each slide.

\section{7. $16 S$ rRNA Microbial Community Analysis}

Mouse fecal DNA was extracted using a FastDNA ${ }^{\mathrm{TM}}$ SPIN Kit (MP Biomedicals, Santa Ana, CA, USA). The $16 \mathrm{~S}$ rRNA gene comprising V3-V4 regions was amplified using a forward primer 338F (5'-ACTCCTACGGGAGGCAGCAG-3') and a reverse primer 806R (5'-GGACTACHVGGGTWTCTAAT-3'). PCR reactions were performed in triplicate: $50 \mu \mathrm{L}$ mixture containing $2 \mu \mathrm{L}$ of each primer $(10 \mu \mathrm{M}), 4 \mu \mathrm{L}$ of dNTPs $(2.5 \mathrm{mM}), 5 \mu \mathrm{L}$ of $10 \times$ Pyrobest Buffer, $0.3 \mu \mathrm{L}$ of Pyrobest DNA Polymerase $(2.5 \mathrm{U} / \mu \mathrm{L})$ and $30 \mathrm{ng}$ of DNA sample. The amplification protocol was as follows: $95{ }^{\circ} \mathrm{C}$ for $5 \mathrm{~min}, 25$ cycles at $95{ }^{\circ} \mathrm{C}$ for $30 \mathrm{~s}, 56{ }^{\circ} \mathrm{C}$ for $30 \mathrm{~s}, 72{ }^{\circ} \mathrm{C}$ for $40 \mathrm{~s}$ and a final extension at $72{ }^{\circ} \mathrm{C}$ for $10 \mathrm{~min}$. Amplicons were extracted from $2 \%$ agarose gels and purified using the AxyPrep DNA Gel Extraction Kit (Axygen Biosciences, Union City, CA, USA). Purified amplicons were paired-end sequenced on the MiSeq Illumina MiSeq platform by Allwegene Technology Inc. (Beijing, China), and 16S rRNA gene sequences were analyzed using the Quantitative Insights Into Microbial Ecology (QIIME) software (Version 1.8, http:/ / qiime.org/) package with the following criteria: 1) trimming sequences over a 50 bp sliding window and discarding truncated reads shorter than 200 bp; 2) less than two nucleotide mismatches in primer matching; 3) assembling the paired reads according to their overlap sequence with a mismatch rate $<0.1 ; 4)$ chimera sequences were identified and removed using Usearch software (version 8.1.1861, http:/ / www.drive5.com/usearch/). All sequences were used for the comparison of relative abundance of bacterial taxa, and were clustered into operational taxonomic units (OTUs) according to a 97\% similarity. The taxonomy of each 16S rRNA gene sequence was analyzed using UCLUST (version 1.2.22, http:/ / www.drive5.com/uclust/downloads1_2_22q.html) against the Silva119 16S rRNA database using a confidence threshold of $90 \%$. PICRUSt analysis was conducted as performed previously [58]. 


\subsection{Statistical Analysis}

Data are presented as means \pm SD. Differences between two groups were analyzed using an unpaired Student's $t$-test. Datasets that involved more than two groups were assessed with one-way analysis variance (ANOVA), along with the Tukey-Kramer test. $p<0.05$ was regarded as statistically significant. Regular analysis was carried out using GraphPad Prism (version 7.0a, GraphPad Software Inc., San Diego, CA, USA).

\section{Conclusions}

In this study, NACOS feeding maintained the stability of intestinal homeostasis in HFD-treated mice, which was accompanied by an elevated abundance of beneficial bacteria (Bifidobacterium, Lactobacillus, Akkermansia, Bacteroides, etc.), the reduced population of pro-inflammatory bacteria (Desulfovibrio) and enhanced gut integrity. Further, NACOS significantly decreased the LPS concentration in the circulation system, alleviated the occurrence of dyslipidemia and inflammation in adipose tissues, and, thus improved hyperglycemic symptoms in mice.

Supplementary Materials: The following are available online at http:/ /www.mdpi.com/1660-3397/16/2/66/s1. Table S1: Ingredient of control diet (CD) and high-fat diet (HFD) in the mouse experiment; Table S2: Primers used in this study; Table S3: Recovery rates of spiking control for LPS ELISA assay; Figure S1: Standard curve of LPS ELISA assay, and LPS with different concentrations was used as spiking control; Figure S2: Intra- \& inter individual assay variation (CV) of LPS ELISA kit (E03L0268, BlueGene Biotech, China); Figure S3: LC-MS spectrum of NACOS; Figure S4: Improvement of NACOS on the lipid levels in liver and blood of HFD-fed mice; Figure S5: Inhibition of NACOS on lipid accumulation in liver tissues of HFD-treated mice; Figure S6: Suppressive effect of NACOS on increment of adipocyte size in abdominal adipose tissues of HFD-treated mice; Figure S7: Effect of NACOS on the relative population of gut microbial bacteria with low abundance in mice after HFD treatment at genus level.

Acknowledgments: We are grateful for the support of the National Natural Science Foundation of China (No. 31570801 and No. 31500747), and the National Programs for High Technology Research and Development (863 Programs, 2014AA093604).

Author Contributions: Yuguang Du and Hongtao Liu designed the study. Junping Zheng, Gong Cheng, Qiongyu Li, Siming Jiao, and Cui Feng were responsible for the acquisition of data. Xiaoming Zhao interpreted the experimental data. Hongtao Liu and Junping Zheng were the major contributors to drafting and revising the manuscript. All authors read and approved the final manuscript.

Conflicts of Interest: The authors declare no conflict of interest.

\section{References}

1. Goldberg, R.B.; Mather, K. Targeting the consequences of the metabolic syndrome in the Diabetes Prevention Program. Arterioscler. Thromb. Vasc. Biol. 2012, 32, 2077-2090. [CrossRef] [PubMed]

2. Cani, P.D.; Neyrinck, A.M.; Fava, F.; Knauf, C.; Burcelin, R.G.; Tuohy, K.M.; Gibson, G.R.; Delzenne, N.M. Selective increases of bifidobacteria in gut microflora improve high-fat-diet-induced diabetes in mice through a mechanism associated with endotoxaemia. Diabetologia 2007, 50, 2374-2383. [CrossRef] [PubMed]

3. Suarez-Zamorano, N.; Fabbiano, S.; Chevalier, C.; Stojanovic, O.; Colin, D.J.; Stevanovic, A.; Veyrat-Durebex, C.; Tarallo, V.; Rigo, D.; Germain, S.; et al. Microbiota depletion promotes browning of white adipose tissue and reduces obesity. Nat. Med. 2015, 21, 1497-1501. [CrossRef] [PubMed]

4. Turnbaugh, P.J.; Backhed, F.; Fulton, L.; Gordon, J.I. Diet-induced obesity is linked to marked but reversible alterations in the mouse distal gut microbiome. Cell Host Microbe 2008, 3, 213-223.

5. Ravussin, Y.; Koren, O.; Spor, A.; LeDuc, C.; Gutman, R.; Stombaugh, J.; Knight, R.; Ley, R.E.; Leibel, R.L. Responses of gut microbiota to diet composition and weight loss in lean and obese mice. Obesity (Silver Spring) 2012, 20, 738-747. [CrossRef] [PubMed]

6. Serino, M.; Luche, E.; Gres, S.; Baylac, A.; Berge, M.; Cenac, C.; Waget, A.; Klopp, P.; Iacovoni, J.; Klopp, C.; et al. Metabolic adaptation to a high-fat diet is associated with a change in the gut microbiota. Gut 2012, 61, 543-553. [CrossRef] [PubMed] 
7. Clavel, T.; Desmarchelier, C.; Haller, D.; Gerard, P.; Rohn, S.; Lepage, P.; Daniel, H. Intestinal microbiota in metabolic diseases: from bacterial community structure and functions to species of pathophysiological relevance. Gut Microbes 2014, 5, 544-551. [CrossRef] [PubMed]

8. Andersson, U.; Branning, C.; Ahrne, S.; Molin, G.; Alenfall, J.; Onning, G.; Nyman, M.; Holm, C. Probiotics lower plasma glucose in the high-fat fed C57BL/6J mouse. Benef. Microbes 2010, 1, 189-196. [CrossRef] [PubMed]

9. Everard, A.; Belzer, C.; Geurts, L.; Ouwerkerk, J.P.; Druart, C.; Bindels, L.B.; Guiot, Y.; Derrien, M.; Muccioli, G.G.; Delzenne, N.M.; et al. Cross-talk between Akkermansia muciniphila and intestinal epithelium controls diet-induced obesity. Proc. Natl. Acad. Sci. USA 2013, 110, 9066-9071. [CrossRef] [PubMed]

10. Shin, N.R.; Lee, J.C.; Lee, H.Y.; Kim, M.S.; Whon, T.W.; Lee, M.S.; Bae, J.W. An increase in the Akkermansia spp. population induced by metformin treatment improves glucose homeostasis in diet-induced obese mice. Gut 2014, 63, 727-735. [CrossRef] [PubMed]

11. Stenman, L.K.; Waget, A.; Garret, C.; Klopp, P.; Burcelin, R.; Lahtinen, S. Potential probiotic Bifidobacterium animalis ssp. lactis 420 prevents weight gain and glucose intolerance in diet-induced obese mice. Benef. Microbes 2014, 5, 437-445. [CrossRef] [PubMed]

12. Ottman, N.; Reunanen, J.; Meijerink, M.; Pietila, T.E.; Kainulainen, V.; Klievink, J.; Huuskonen, L.; Aalvink, S.; Skurnik, M.; Boeren, S.; et al. Pili-like proteins of Akkermansia muciniphila modulate host immune responses and gut barrier function. PLoS One 2017, 12, e0173004. [CrossRef] [PubMed]

13. Johansson, M.E.; Larsson, J.M.; Hansson, G.C. The two mucus layers of colon are organized by the MUC2 mucin, whereas the outer layer is a legislator of host-microbial interactions. Proc. Natl. Acad. Sci. USA 2011, 108, 4659-4665. [CrossRef] [PubMed]

14. Cani, P.D.; Possemiers, S.; Van de Wiele, T.; Guiot, Y.; Everard, A.; Rottier, O.; Geurts, L.; Naslain, D.; Neyrinck, A.; Lambert, D.M.; et al. Changes in gut microbiota control inflammation in obese mice through a mechanism involving GLP-2-driven improvement of gut permeability. Gut 2009, 58, 1091-1103. [CrossRef] [PubMed]

15. Khare, P.; Jagtap, S.; Jain, Y.; Baboota, R.K.; Mangal, P.; Boparai, R.K.; Bhutani, K.K.; Sharma, S.S.; Premkumar, L.S.; Kondepudi, K.K.; et al. Cinnamaldehyde supplementation prevents fasting-induced hyperphagia, lipid accumulation, and inflammation in high-fat diet-fed mice. Biofactors 2016, 42, 201-211. [PubMed]

16. Cani, P.D.; Amar, J.; Iglesias, M.A.; Poggi, M.; Knauf, C.; Bastelica, D.; Neyrinck, A.M.; Fava, F.; Tuohy, K.M.; Chabo, C.; et al. Metabolic endotoxemia initiates obesity and insulin resistance. Diabetes 2007, 56, 1761-1772. [CrossRef] [PubMed]

17. Blasco-Baque, V.; Serino, M.; Burcelin, R. Metabolic therapy at the edge between human hosts and gut microbes. Ann. Pharm. Fr. 2013, 71, 34-41. [CrossRef] [PubMed]

18. Childs, C.E.; Roytio, H.; Alhoniemi, E.; Fekete, A.A.; Forssten, S.D.; Hudjec, N.; Lim, Y.N.; Steger, C.J.; Yaqoob, P.; Tuohy, K.M.; et al. Xylo-oligosaccharides alone or in synbiotic combination with Bifidobacterium animalis subsp. lactis induce bifidogenesis and modulate markers of immune function in healthy adults: A double-blind, placebo-controlled, randomised, factorial cross-over study. Br. J. Nutr. 2014, 111, 1945-1956. [CrossRef] [PubMed]

19. Goh, Y.J.; Klaenhammer, T.R. Genetic mechanisms of prebiotic oligosaccharide metabolism in probiotic microbes. Annu. Rev. Food Sci. Technol. 2015, 6, 137-156. [CrossRef] [PubMed]

20. Dai, Z.; Lyu, W.; Xie, M.; Yuan, Q.; Ye, H.; Hu, B.; Zhou, L.; Zeng, X. Effects of alpha-Galactooligosaccharides from Chickpeas on High-Fat-Diet-Induced Metabolic Syndrome in Mice. J. Agric. Food Chem. 2017, 65, 3160-3166. [CrossRef] [PubMed]

21. Aranda-Martinez, A.; Lopez-Moya, F.; Lopez-Llorca, L.V. Cell wall composition plays a key role on sensitivity of filamentous fungi to chitosan. J. Basic Microbiol. 2016, 56, 1059-1070. [CrossRef] [PubMed]

22. Mhamdi, S.; Ktari, N.; Hajji, S.; Nasri, M.; Sellami Kamoun, A. Alkaline proteases from a newly isolated Micromonospora chaiyaphumensis S103: Characterization and application as a detergent additive and for chitin extraction from shrimp shell waste. Int. J. Biol. Macromol. 2017, 94, 415-422. [CrossRef] [PubMed]

23. Ohnuma, T.; Numata, T.; Osawa, T.; Inanaga, H.; Okazaki, Y.; Shinya, S.; Kondo, K.; Fukuda, T.; Fukamizo, T. Crystal structure and chitin oligosaccharide-binding mode of a 'loopful' family GH19 chitinase from rye, Secale cereale, seeds. FEBS J. 2012, 279, 3639-3651. [CrossRef] [PubMed] 
24. Jo, S.H.; Ha, K.S.; Moon, K.S.; Kim, J.G.; Oh, C.G.; Kim, Y.C.; Apostolidis, E.; Kwon, Y.I. Molecular weight dependent glucose lowering effect of low molecular weight Chitosan Oligosaccharide (GO2KA1) on postprandial blood glucose level in SD rats model. Int. J. Mol. Sci. 2013, 14, 14214-14224. [CrossRef] [PubMed]

25. Kim, H.J.; Ahn, H.Y.; Kwak, J.H.; Shin, D.Y.; Kwon, Y.I.; Oh, C.G.; Lee, J.H. The effects of chitosan oligosaccharide (GO2KA1) supplementation on glucose control in subjects with prediabetes. Food Funct. 2014, 5, 2662-2669. [CrossRef] [PubMed]

26. Lee, H.W.; Park, Y.S.; Choi, J.W.; Yi, S.Y.; Shin, W.S. Antidiabetic effects of chitosan oligosaccharides in neonatal streptozotocin-induced noninsulin-dependent diabetes mellitus in rats. Biol. Pharm. Bull. 2003, 26, 1100-1103. [CrossRef] [PubMed]

27. Yuan, W.P.; Liu, B.; Liu, C.H.; Wang, X.J.; Zhang, M.S.; Meng, X.M.; Xia, X.K. Antioxidant activity of chito-oligosaccharides on pancreatic islet cells in streptozotocin-induced diabetes in rats. World J. Gastroenterol. 2009, 15, 1339-1345. [CrossRef] [PubMed]

28. Kim, J.G.; Jo, S.H.; Ha, K.S.; Kim, S.C.; Kim, Y.C.; Apostolidis, E.; Kwon, Y.I. Effect of long-term supplementation of low molecular weight chitosan oligosaccharide (GO2KA1) on fasting blood glucose and $\mathrm{HbA} 1 \mathrm{c}$ in $\mathrm{db} / \mathrm{db}$ mice model and elucidation of mechanism of action. BMC Complement. Altern. Med. 2014, 14, 272. [CrossRef] [PubMed]

29. Kim, S.K.; Park, P.J.; Yang, H.P.; Han, S.S. Subacute toxicity of chitosan oligosaccharide in Sprague-Dawley rats. Arzneimittelforschung 2001, 51, 769-774. [CrossRef] [PubMed]

30. Ouyang, Q.Q.; Zhao, S.; Li, S.D.; Song, C. Application of Chitosan, Chitooligosaccharide, and Their Derivatives in the Treatment of Alzheimer's Disease. Mar. Drugs 2017, 15, 322. [CrossRef] [PubMed]

31. Park, B.K.; Kim, M.M. Applications of chitin and its derivatives in biological medicine. Int. J. Mol. Sci. 2010, 11, 5152-5164. [CrossRef] [PubMed]

32. Azuma, K.; Osaki, T.; Minami, S.; Okamoto, Y. Anticancer and anti-inflammatory properties of chitin and chitosan oligosaccharides. J. Funct. Biomater. 2015, 6, 33-49. [CrossRef] [PubMed]

33. Neyrinck, A.M.; Possemiers, S.; Verstraete, W.; De Backer, F.; Cani, P.D.; Delzenne, N.M. Dietary modulation of clostridial cluster XIVa gut bacteria (Roseburia spp.) by chitin-glucan fiber improves host metabolic alterations induced by high-fat diet in mice. J. Nutr. Biochem. 2012, 23, 51-59. [CrossRef] [PubMed]

34. Mateos-Aparicio, I.; Mengibar, M.; Heras, A. Effect of chito-oligosaccharides over human faecal microbiota during fermentation in batch cultures. Carbohydr. Polym. 2016, 137, 617-624. [CrossRef] [PubMed]

35. Masuda, S.; Azuma, K.; Kurozumi, S.; Kiyose, M.; Osaki, T.; Tsuka, T.; Itoh, N.; Imagawa, T.; Minami, S.; Sato, K.; et al. Anti-tumor properties of orally administered glucosamine and $N$-acetyl-D-glucosamine oligomers in a mouse model. Carbohydr. Polym. 2014, 111, 783-787. [CrossRef] [PubMed]

36. Huang, L.; Chen, J.; Cao, P.; Pan, H.; Ding, C.; Xiao, T.; Zhang, P.; Guo, J.; Su, Z. Anti-obese effect of glucosamine and chitosan oligosaccharide in high-fat diet-induced obese rats. Mar. Drugs 2015, 13, 2732-2756. [CrossRef] [PubMed]

37. Fuentes, E.; Fuentes, F.; Vilahur, G.; Badimon, L.; Palomo, I. Mechanisms of chronic state of inflammation as mediators that link obese adipose tissue and metabolic syndrome. Mediators Inflamm. 2013, 2013, 136584. [CrossRef] [PubMed]

38. Musso, G.; Gambino, R.; Cassader, M. Obesity, diabetes, and gut microbiota: The hygiene hypothesis expanded? Diabetes Care 2010, 33, 2277-2284. [CrossRef] [PubMed]

39. Wang, S.L.; Lin, H.T.; Liang, T.W.; Chen, Y.J.; Yen, Y.H.; Guo, S.P. Reclamation of chitinous materials by bromelain for the preparation of antitumor and antifungal materials. Bioresour. Technol. 2008, 99, 4386-4393. [CrossRef] [PubMed]

40. Qin, C.; Zhang, Y.; Liu, W.; Xu, L.; Yang, Y.; Zhou, Z. Effects of chito-oligosaccharides supplementation on growth performance, intestinal cytokine expression, autochthonous gut bacteria and disease resistance in hybrid tilapia Oreochromis niloticus female symbol x Oreochromis aureus male symbol. Fish Shellfish Immunol 2014, 40, 267-274. [CrossRef] [PubMed]

41. Liu, B.; Liu, W.S.; Han, B.Q.; Sun, Y.Y. Antidiabetic effects of chitooligosaccharides on pancreatic islet cells in streptozotocin-induced diabetic rats. World J. Gastroenterol. 2007, 13, 725-731. [CrossRef] [PubMed]

42. Collins, K.H.; Paul, H.A.; Hart, D.A.; Reimer, R.A.; Smith, I.C.; Rios, J.L.; Seerattan, R.A.; Herzog, W. A High-Fat High-Sucrose Diet Rapidly Alters Muscle Integrity, Inflammation and Gut Microbiota in Male Rats. Sci. Rep. 2016, 6, 37278. [CrossRef] [PubMed] 
43. Flemer, B.; Gaci, N.; Borrel, G.; Sanderson, I.R.; Chaudhary, P.P.; Tottey, W.; O’Toole, P.W.; Brugere, J.F. Fecal microbiota variation across the lifespan of the healthy laboratory rat. Gut Microbes 2017, 8, 428-439. [CrossRef] [PubMed]

44. Chassaing, B.; Etienne-Mesmin, L.; Gewirtz, A.T. Microbiota-liver axis in hepatic disease. Hepatology 2014, 59, 328-339. [CrossRef] [PubMed]

45. Koropatkin, N.M.; Cameron, E.A.; Martens, E.C. How glycan metabolism shapes the human gut microbiota. Nat. Rev. Microbiol. 2012, 10, 323-335. [CrossRef] [PubMed]

46. Larsen, N.; Vogensen, F.K.; van den Berg, F.W.; Nielsen, D.S.; Andreasen, A.S.; Pedersen, B.K.; Al-Soud, W.A.; Sorensen, S.J.; Hansen, L.H.; Jakobsen, M. Gut microbiota in human adults with type 2 diabetes differs from non-diabetic adults. PLoS One 2010, 5, e9085. [CrossRef] [PubMed]

47. Yan, H.; Lu, J.; Wang, Y.; Gu, W.; Yang, X.; Yu, J. Intake of total saponins and polysaccharides from Polygonatum kingianum affects the gut microbiota in diabetic rats. Phytomedicine 2017, 26, 45-54. [CrossRef] [PubMed]

48. Everard, A.; Lazarevic, V.; Derrien, M.; Girard, M.; Muccioli, G.G.; Neyrinck, A.M.; Possemiers, S.; Van Holle, A.; Francois, P.; de Vos, W.M.; et al. Responses of gut microbiota and glucose and lipid metabolism to prebiotics in genetic obese and diet-induced leptin-resistant mice. Diabetes 2011, 60, 2775-2786. [CrossRef] [PubMed]

49. Foley, M.H.; Cockburn, D.W.; Koropatkin, N.M. The Sus operon: A model system for starch uptake by the human gut Bacteroidetes. Cell. Mol. Life Sci. 2016, 73, 2603-2617. [CrossRef] [PubMed]

50. Rabot, S.; Membrez, M.; Blancher, F.; Berger, B.; Moine, D.; Krause, L.; Bibiloni, R.; Bruneau, A.; Gerard, P.; Siddharth, J.; et al. High fat diet drives obesity regardless the composition of gut microbiota in mice. Sci. Rep. 2016, 6, 32484. [CrossRef] [PubMed]

51. Arora, T.; Seyfried, F.; Docherty, N.G.; Tremaroli, V.; le Roux, C.W.; Perkins, R.; Backhed, F. Diabetes-associated microbiota in fa/fa rats is modified by Roux-en-Y gastric bypass. ISME J. 2017, 11, 2035-2046. [CrossRef] [PubMed]

52. Bordalo Tonucci, L.; Dos Santos, K.M.; De Luces Fortes Ferreira, C.L.; Ribeiro, S.M.; De Oliveira, L.L.; Martino, H.S. Gut microbiota and probiotics: Focus on diabetes mellitus. Crit. Rev. Food Sci. Nutr. 2017, 57, 2296-2309. [CrossRef] [PubMed]

53. Marcobal, A.; Sonnenburg, J.L. Human milk oligosaccharide consumption by intestinal microbiota. Clin. Microbiol. Infect. 2012, 18, 12-15. [CrossRef] [PubMed]

54. Hale, V.L.; Chen, J.; Johnson, S.; Harrington, S.C.; Yab, T.C.; Smyrk, T.C.; Nelson, H.; Boardman, L.A.; Druliner, B.R.; Levin, T.R.; et al. Shifts in the Fecal Microbiota Associated with Adenomatous Polyps. Cancer Epidemiol. Biomarkers Prev. 2017, 26, 85-94. [CrossRef] [PubMed]

55. Zhang-Sun, W.; Augusto, L.A.; Zhao, L.; Caroff, M. Desulfovibrio desulfuricans isolates from the gut of a single individual: Structural and biological lipid A characterization. FEBS Lett. 2015, 589, 165-171. [CrossRef] [PubMed]

56. Zhou, S.S.; Xu, J.; Zhu, H.; Wu, J.; Xu, J.D.; Yan, R.; Li, X.Y.; Liu, H.H.; Duan, S.M.; Wang, Z.; et al. Gut microbiota-involved mechanisms in enhancing systemic exposure of ginsenosides by coexisting polysaccharides in ginseng decoction. Sci. Rep. 2016, 6, 22474. [CrossRef] [PubMed]

57. Chen, K.; Chen, H.; Faas, M.M.; de Haan, B.J.; Li, J.; Xiao, P.; Zhang, H.; Diana, J.; de Vos, P.; Sun, J. Specific inulin-type fructan fibers protect against autoimmune diabetes by modulating gut immunity, barrier function, and microbiota homeostasis. Mol. Nutr. Food Res. 2017, 61. [CrossRef] [PubMed]

58. Langille, M.G.; Zaneveld, J.; Caporaso, J.G.; McDonald, D.; Knights, D.; Reyes, J.A.; Clemente, J.C.; Burkepile, D.E.; Vega Thurber, R.L.; Knight, R.; et al. Predictive functional profiling of microbial communities using $16 \mathrm{~S}$ rRNA marker gene sequences. Nat. Biotechnol. 2013, 31, 814-821. [CrossRef] [PubMed]

(C) 2018 by the authors. Licensee MDPI, Basel, Switzerland. This article is an open access article distributed under the terms and conditions of the Creative Commons Attribution (CC BY) license (http://creativecommons.org/licenses/by/4.0/). 